\title{
Student Retention Barriers in a Chemical Engineering Program
}

\section{Dr. Marina Miletic, University of New Mexico}

Dr. Marina Miletic served as a Lecturer in the Department of Chemical \& Biomolecular Engineering at the University of Illinois at Urbana-Champaign for eight years. She taught Senior Design and Unit Operations among other courses and helped establish one of the nation's first week-long Chemical Engineering summer camps for girls. Her research has focused on promoting concept-based learning in the classroom, developing Chemical Engineering video lectures, studying the efficacy of remote web-controlled Unit Operations experiments, and incorporating Design throughout the Chemical Engineering curriculum. She currently works as a freelance Engineering Education Consultant and Chemical Engineer. She is the Project Manager for NSF grant \#1623105, IUSE/PFE:RED: FACETS: Formation of Accomplished Chemical Engineers for Transforming Society, for which she is advising and coordinating assessment.

\section{Dr. Abhaya K. Datye, University of New Mexico}

Abhaya Datye has been on the faculty at the University of New Mexico after receiving his $\mathrm{PhD}$ in Chemical Engineering at the University of Michigan in 1984. He is presently Chair of the department and Distinguished Regents Professor of Chemical \& Biological Engineering. From 1994-2014 he served as Director of the Center for Microengineered Materials, a strategic research center at UNM that reports to the Vice President for Research. He is also the founding director of the graduate interdisciplinary program in Nanoscience and Microsystems, the first program at UNM to span three schools and colleges and the Anderson Business School. He served as director of this program from 2007 - 2014. His research interests are in heterogeneous catalysis, materials characterization and nanomaterials synthesis. His research group has pioneered the development of electron microscopy tools for the study of catalysts.

\section{Dr. Vanessa Svihla, University of New Mexico}

Dr. Vanessa Svihla is a learning scientist and associate professor at the University of New Mexico in the Organization, Information \& Learning Sciences program and in the Chemical \& Biological Engineering Department. She served as Co-PI on an NSF RET Grant and a USDA NIFA grant, and is currently co-PI on three NSF-funded projects in engineering and computer science education, including a Revolutionizing Engineering Departments project. She was selected as a National Academy of Education / Spencer Postdoctoral Fellow and a 2018 NSF CAREER awardee in engineering education research. Dr. Svihla studies learning in authentic, real world conditions; this includes a two-strand research program focused on (1) authentic assessment, often aided by interactive technology, and (2) design learning, in which she studies engineers designing devices, scientists designing investigations, teachers designing learning experiences and students designing to learn.

\section{Prof. Eva Chi, University of New Mexico}

Eva Chi is an Associate Professor in the Department of Chemical and Biological Engineering Department at the University of New Mexico. The research in her lab is focused on understanding the dynamics and structures of macromolecular assemblies including proteins, polymers, and lipid membranes. Undergraduates, graduate students, and postdoctoral scholars are trained in a multidisciplinary environment, utilizing modern methodologies to address important problems at the interface between chemistry, physics, engineering, and biology preparing the trainees for careers in academe, national laboratories, and industry. In addition to research, she devotes significant time developing and implementing effective pedagogical approaches in her teaching of undergraduate courses to train engineers who are critical thinkers, problem solvers, and able to understand the societal contexts in which they are working to addressing the grand challenges of the 21 st century.

\section{Dr. Jamie Gomez, University of New Mexico}

Jamie Gomez, Ph.D., is a Senior Lecturer III in the department of Chemical \& Biological Engineering (CBE) at the University of New Mexico. She is a co- principal investigator for the following National 
Science Foundation (NSF) funded projects: Professional Formation of Engineers: Research Initiation in Engineering Formation (PFE: RIEF) - Using Digital Badging and Design Challenge Modules to Develop Professional Identity; Professional Formation of Engineers: REvolutionizing engineering and computer science Departments (IUSE PFE $\backslash$ RED) - Formation of Accomplished Chemical Engineers for Transforming Society. She is a member of the CBE department's ABET and Undergraduate Curriculum Committee, as well as faculty advisor for several student societies. She is the instructor of several courses in the CBE curriculum including the Material and Energy Balances, junior laboratories and Capstone Design courses. She is associated with several professional organizations including the American Institute of Chemical Engineers (AIChE) and American Society of Chemical Engineering Education (ASEE) where she adopts and contributes to innovative pedagogical methods aimed at improving student learning and retention.

\section{Dr. Pil Kang, University of New Mexico}

Sung "Pil" Kang is an assistant professor at the University of New Mexico. His academic interests include change management, change model validation, and mindset evolution. He may be reached at pilkang@unm.edu

\section{Prof. Sang M. Han, University of New Mexico}

Dr. Han is a Regents Professor in the Departments of Chemical \& Biological Engineering and Electrical \& Computer Engineering at the University of New Mexico. He earned his Ph.D. in chemical engineering from the University of California at Santa Barbara and his B.S. in chemical engineering with honors from the University of California at Berkeley. Dr. Han has over 25 years of experience in electronic and photonic materials engineering and fabrication. His current research topics include (1) writable/rewritable quantum structures by stress patterning; (2) low-cost, crack-tolerant, advanced metallization for solar cell durability; (3) thin film processing and nanoscale surface corrugation for enhanced light trapping for photovoltaic devices; and (4) microsphere-based manufacturable coatings for radiative cooling. He has close to 70 publications in peer-reviewed journals and over 200 invited/contributed papers at academic institutions, national laboratories, and conferences. He received a UNM Junior Faculty Research Excellence Award in 2005 and an NSF Career Award in 2001. He is a recipient of STC.UNM Innovation Award consecutively from 2009 to 2018, and he was elected as the 2018 STC.UNM Innovation Fellow. Dr. Han holds 17 UNM-affiliated U.S. patents and 6 pending U.S. and PCT patent applications. He currently serves as the Chief Technical Officer of Osazda Energy LLC, a startup company based on his intellectual property generated at UNM. Prior to his entrepreneurial venture, Dr. Han served as the main campus faculty member of the STC.UNM Board of Directors from 2015 to 2016.

\section{Dr. Yan Chen, University of New Mexico}

Yan Chen is a Postdoctoral Fellow in the Departments of Chemical and Biological Engineering at the University of New Mexico. Her research interests focus on computer-supported collaborative learning, online learning and teaching, and educational equity for multicultural/multiethnic education.

\section{Ms. Catherine Anne Hubka, University of New Mexico}

Catherine (Cat) Hubka, MFA, holds appointments at the University of New Mexico in the Departments of Chemical and Biological Engineering (CBE), Nuclear Engineering, and Department of English. For CBE, she is embedded in the 300 and 400 labs where she supports curriculum redesign focused on incorporating content-based writing approaches. In the Nuclear Engineering Department, she supports writing in 300-level lab courses by designing writing assignments that scaffold to formal reports. In the Department of English, Cat teaches in the Core Writing Program where her pedagogy incorporates creative writing workshop strategies and collaborative writing for traditional and nontraditional, at-risk student populations. 


\section{Student Retention Barriers in a Chemical Engineering Program}

In this research paper, we examine and discuss factors that impact student retention at a large Hispanic-serving chemical engineering program situated in a public research university. As part of a Revolutionizing Engineering and Computer Science Departments five year grant from the National Science Foundation, our department has changed its chemical engineering curriculum by incorporating Community-, Industry-, Research-, and/or Entrepreneurship-based design challenges through the core curriculum, engaging students in Writing-Across-the-Curriculum (WAC), offering faculty professional development workshops, and implementing a digital badging system to help students take ownership of their competencies. Such fundamental changes to department structure and curriculum elicit many questions about outcomes and student retention. This paper outlines some of the key barriers to successful student retention in our program by identifying conspicuous factors linked to student attrition and retention.

The students in our program are atypically diverse compared to those found at other large Research I universities. According to student surveys and enrollment data, our students are 43\% female, $45 \%$ are Latinx, $5 \%$ are Native American, $28 \%$ are first-generation college attendees, $27 \%$ are from lower income families, 33\% speak a language other than English at home, 52\% of students work more than 10 hours per week while in college, and 52\% of students' mothers and $48 \%$ of their fathers have not earned a college degree.

Our examination of Enrollment Management retention and attrition data show that students transfer into our program largely from Biochemistry, Biology, and Chemistry programs. When students transfer out, they predominately leave to those three majors as well as engineering majors such as Mechanical and Civil. A promising finding is that over 50\% of our four-year graduates are first-generation college students, even though first-generation college attendees represent only around one-third of our students. This result suggests that first generation students are more likely to stay in our chemical engineering program and finish their degree on time, compared to non-first generation students who are more likely to transfer into and out of the program. Another positive finding is that females, Hispanic students, and Asian students are retained at around $40 \%$, the same overall rate as all students combined. This Hispanic student retention rate is higher than the national average of $32 \%$ [1]. Students who drop out of our program and the university entirely, are disproportionately male students who attended lowerrated high schools and are usually not first-generation college students. These students were far more likely to take remedial math, chemistry, and physics courses, earned around one letter grade lower in math, chemistry, and physics courses compared to chemical engineering graduates, and were far less likely to have tested out of or transferred credits for these courses. These retention analyses have been instrumental in helping us aim the direction of support and programmatic changes offered to students.

\section{Introduction}

Pedagogical literature cites numerous secondary education, post-secondary education, climate, and demographic factors as predictors of student retention in engineering programs [2]. Traditionally, retention in engineering programs has been predicted by numerous student background factors. The idea of "curricular momentum" explored by Aldeman et al. is one 
hypothesis surrounding engineering student retention and attrition which begins in high school. For example, engineering attracts a high percentage of students who exhibit a consistent career goal starting in high school and a low percentage of students who change their career objectives [3].

Over the past 40 years, mathematics performance and preparation emerged as a common prophetic theme in engineering education retention. The highest level of mathematics studied in high school is strongly correlated with degree completion in engineering and this is significantly correlated for students from a lower socioeconomic environment [3]. Mau et al. showed that for women and underrepresented students, retention in engineering was best predicted by preuniversity preparation and math self-efficacy [4]. Some have explained the correlation between math and engineering retention by noting that undergraduate engineering curricula devote about one out of every seven credits to mathematics, more hours than any other non-major course [3].

More recently however, the literature has been focused on examining climate and demographic factors and their confluence or coincidence with other elements such as academic preparation. Many studies have examined women's course performance and retention in engineering compared to men. Even when women's academic background, college admissions test scores, motivation to study, pre-engineering credentials, and family education level were higher than those of men, men generally earned higher average grades and a greater percentage of A's in technical courses [5] [3], though there are more recent studies that show these course grade gaps have narrowed [6]. Women who leave engineering tend to have higher grades than the men who leave [3] [6], however, overall, women and men tend to drop out of engineering programs at the same rate by senior year [1]. More recent studies show that although attrition of female students is essentially the same as that of men [1] [6], retention of underrepresented students remains lower [1] [7]. Current nationwide data show that Hispanic students represent 9\% of enrolled engineering students and they are retained at an overall rate of $32 \%$, which is lower than the national average of $54 \%$ for all engineering students [1].

Likewise, over the past 20 years, in-classroom and out-of-classroom climate has gained marked attention as a significant factor contributing to student persistence in engineering. Marra et el. cited "lack of belonging" as the primary reason for engineering attrition among all groups of students, especially, but not only including, underrepresented students. Albeit more nebulous and less specifically identifiable, this factor was more significant than others such as poor teaching, poor advising, and difficult coursework [6]. Not surprisingly, climate is largely influenced by student-faculty interactions, as numerous studies have shown lack of quality, persistent interaction with faculty leads to lower GPA, lower self-efficacy, and higher attrition [8] [9]. Other studies have cited related issues of curriculum boredom, lack of academic confidence [8], poor understanding of what engineering is [3], feelings of overwhelm, and lack of integration into the engineering culture [10] as reasons for students leaving STEM majors.

A longitudinal study, similar to the one explored in this paper, followed the performance of 124 chemical engineering students through the introductory freshman chemical engineering course and the sophomore level Mass and Energy Balances course and found that course grades, high school preparation, and other background factors were significantly correlated to retention and performance [11]. The study found that students who performed better in the freshman course 
were more likely to be from an urban/suburban home environment compared to a rural or small town, have spent less than 10 hours per week working, have devoted between 2-12 hours a week to extracurricular activities (rather than more than 12 hours or less than 2 hours), and have a father with some college education. The study also found that Mass and Energy Balances course performance was positively correlated to higher SAT mathematics and verbal scores, freshman year GPA, and higher grades in freshman mathematics, physics, chemistry, and English courses [11].

While there have been numerous contributions in the literature regarding this topic, the purpose of this current paper is not to present an exhaustive examination of all barriers or contributors to retention. Rather, this article will focus on some possible demographic and course performance factors which we have observed correlate to student retention or attrition at our university.

\section{Research Questions}

Overall, our project seeks to answer the following research questions:

1. What are significant demographics- and course-related barriers affecting student progression through the chemical engineering program?

2. What does this information tell us about how support should be targeted to students to address these barriers and improve retention?

\section{Research Context and Motivation}

Our department is currently one of 21 across the country which has earned National Science Foundation funding through the Directorates for Engineering, Computing, and Information Science and Engineering program for Revolutionizing Engineering and Computer Science Departments (RED). These are multi-year grants, led by department chairs as head PIs to promote groundbreaking, scalable, and sustainable improvements in undergraduate engineering and computer science programs. Our work specifically aims to fundamentally change our undergraduate chemical engineering program by embedding Community-, Industry-, Research-, and/or Entrepreneurship-based design challenges through the core curriculum, engaging students in writing across our series of chemical engineering laboratory courses, delivering faculty professional development workshops, and implementing a departmental digital badging system to promote and acknowledge student competencies. Our five-year project is currently in its fourth year, with the first year generally focused on collection of baseline data.

A key aim of these initiatives is to promote retention of students in our program, especially those who are underrepresented. As the project has progressed, we have tracked retention of our program's students prior to and throughout our project progression to examine whether our interventions have affected student persistence. This paper reflects some of the current conclusions drawn from this retention analysis.

\section{Data Analysis Methods}

Data presented here are of students enrolled in the program before and after the project began. We have analyzed and compared historic student demographics, course grades, academic 
progression, retention, and graduation rates. We obtained student demographics, transcripts, and course grade information through the university's enrollment management office. We also collected student demographics information via student survey within department-specific courses. Enrollment management data provided us with students' high school background, transfer credits, prior education, their major before and after transferring to the department, and grades in remedial and regular level math, physics, and chemistry. The surveys students take in courses are both beginning-of-the-semester and end-of-the-semester, occur 3 times a year, and are assigned points for completion to help ensure a representative data set. We obtained IRB approval for survey administration and all survey data used for study are from consented students. Unlike Enrollment Management data, course surveys provide more immediate and first-hand information on students' current activities and preparation, and these data tend to consistently resemble the enrollment management data provided by the university.

\section{Limitations of this Study}

These data presented only reflect students who took the introductory 101 chemical engineering course at our university within the past 10 years or less ( $\mathrm{N}=978$ or fewer.) This study did not examine student retention or attrition across the university as a whole or even across engineering departments. Because each student and their complete transcript was evaluated extensively for many factors, an analysis of students outside of chemical engineering would have been cost prohibitive.

Though in 2017, as a result of our RED grant, we established a revised curriculum featuring design challenges, writing throughout the lab sequence, and administration of digital badges, we cannot yet conclusively determine the effect of these course improvements on retention and performance since retention data for our program is highly variable year-to-year and therefore more data across additional years need to be collected.

\section{Results and Discussion}

This discussion will start with an analysis of demographics and then explore correlations between grades in key courses and student retention. Our demographics analysis was featured in greater detail in previous work [12]. Some aspects are reviewed here to highlight the diverse background of our students and describe retention patterns.

\section{Demographics Analysis}

A combination of course survey data and campus Enrollment Management data were used to determine the demographic make-up of our students. On average, our graduates are $43 \%$ women, 45\% Latinx/Hispanic, 33\% White, 7\% Asian, 5\% Native/American Indian, 5\% Two or more races, and 5\% International, described as "Non-Res Alien." Our female, Latinx, and Native American populations are by percentage higher than the national averages for chemical engineering programs. Nationally, $32 \%$ of chemical engineering graduates are women while African American, American Indian/Alaska Native, and Hispanics collectively earn 13\% of B.S. degrees in chemical engineering [1]. Among our chemical engineering student population, 33\% speak a language other than English at home, $28 \%$ are first generation college attendees, $52 \%$ of 
students work more than 10 hours per week while in college, $27 \%$ are from lower income families, and $52 \%$ of students' mothers and $48 \%$ of their fathers have not earned a college degree.

Figure 1 summarizes some of the demographics and academic characteristics of an average chemical engineering graduate from our program. Graduates from our program are more likely to have a high university GPA, transfer many science, math, and non-STEM credit requirements from other colleges or universities, have an ACT score around the 78\% percentile, attended a public high school with an average $\mathrm{B}$ to $\mathrm{B}+$ rating [13], and be a first generation college student in their family.

\section{Chemical Engineering students who have graduated or are close to graduating with a CHE degree, $\mathrm{N}=105$}

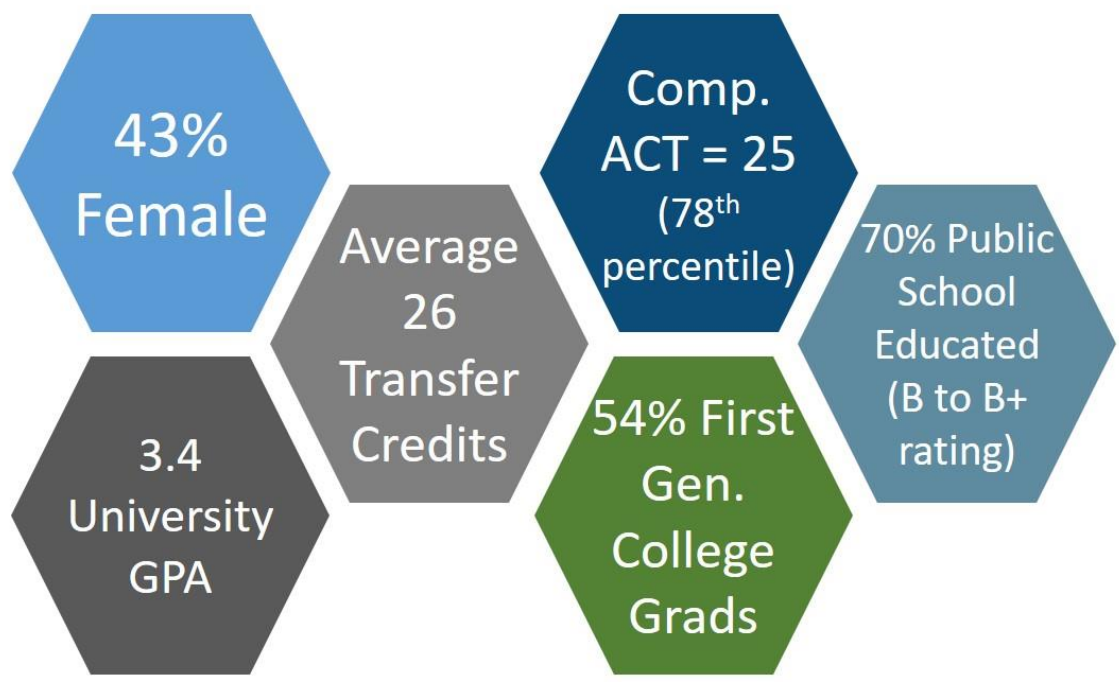

Figure 1: Characteristics of chemical engineering students who have graduated or will soon graduate with chemical engineering degrees from our program, examined among the cohort of 2014 and 2015 first year chemical engineering students.

A positive finding is that $54 \%$ of our four-year graduates are first-generation college students, even though first-generation college attendees represent only $28 \%$ of our enrolled students. This suggests that first generation college students, once having chosen chemical engineering as a major, are more likely to stay compared to non-first generation college attendees.

The majority of students who transfer into our program do so from Biochemistry, Biology, or Chemistry programs within the university. Students who transfer out of the chemical engineering program transfer to Biology, Biochemistry, Business Administration, and Chemistry most prevalently. Students who drop out of our program and also out of university, are disproportionately male students who attended lower-rated high schools (B- rating or below) [13] and are usually not first-generation college students. 
Figure 2 shows retention of students in our program from $1^{\text {st }}$ to $4^{\text {th }}$ year among a cohort of 2009 2017 first year students. Approximately 40\% of students are lost to other majors or drop out of the university between the $1^{\text {st }}$ and $2^{\text {nd }}$ year, representing the largest rate of attrition in the four year sequence. A second round of attrition occurs between the $2^{\text {nd }}$ and $3^{\text {rd }}$ years, representing another $20 \%$ loss. There is virtually no attrition of students between the $3^{\text {rd }}$ and $4^{\text {th }}$ years, nor between the $4^{\text {th }}$ and $5^{\text {th }}$ years, if taken. Hence, overall retention of students from $1^{\text {st }}$ to $4^{\text {th }}$ year is $41 \%$.

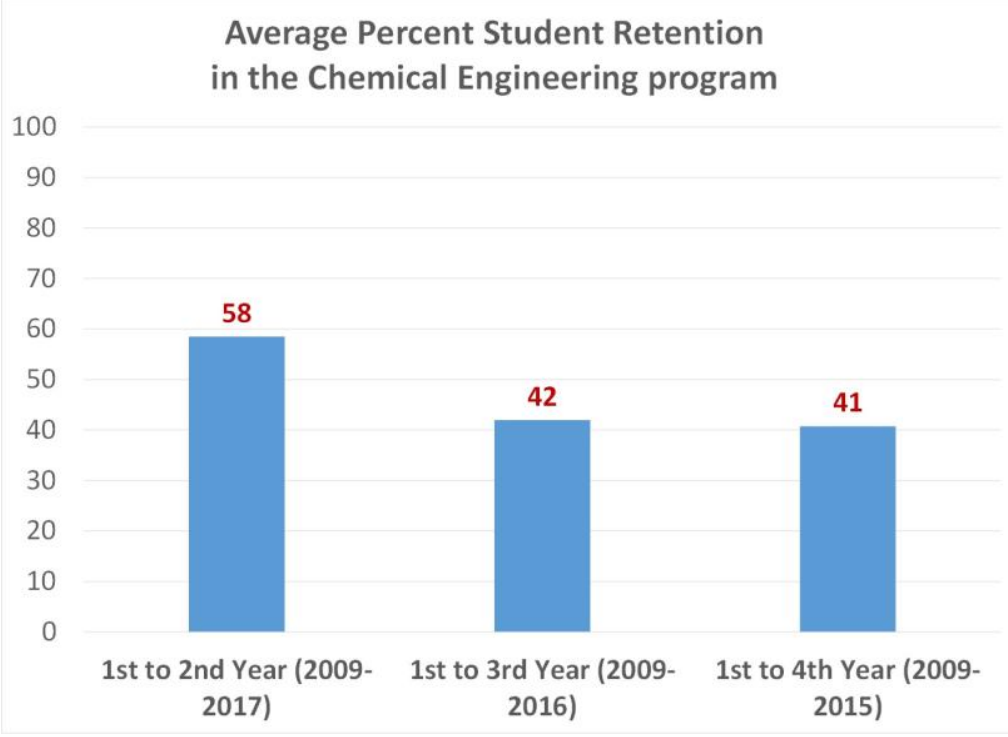

Figure 2: Average percent student retention based on $1^{\text {st }}, 2^{\text {nd }}, 3^{\text {rd }}$, and $4^{\text {th }}$ year course enrollments among 2009-2017 first year students enrolled in our program. $N=978$. Dates signify academic year of freshman chemical engineering course enrollment.

The retention rates of students based on race is shown in Figure 3.

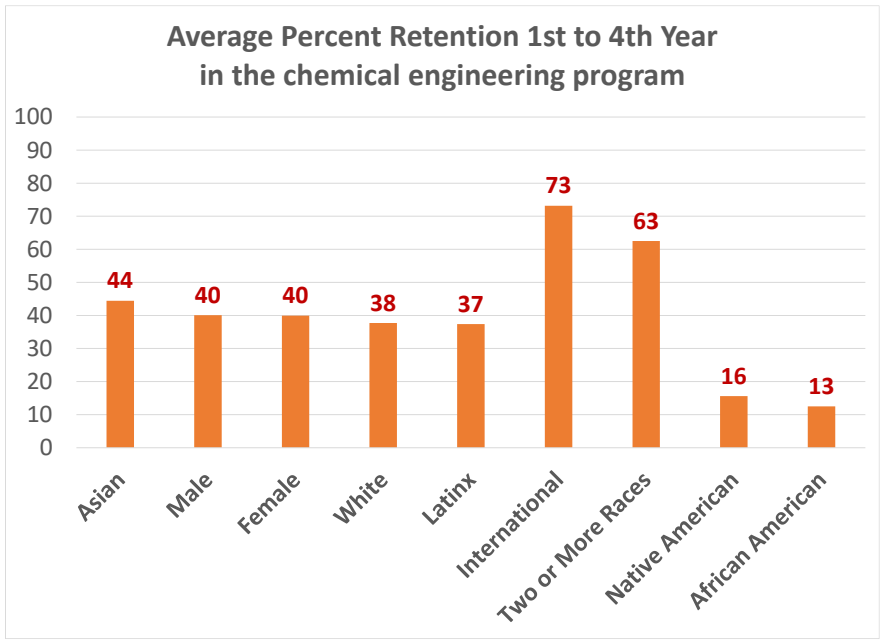


Figure 3: Average percent retention from $1^{\text {st }}$ to $4^{\text {th }}$ year of students in our chemical engineering program based on race, for cohorts enrolled in the first year chemical engineering course Fall 2009 through Spring 2016. N=978.

An encouraging finding is that in our program, men, women, Latinx students, White students, and Asian students are retained at around $40 \%$, the same overall rate as all students combined. This Latinx student retention rate is higher than the national average of $32 \%$ [1]. Students who are two or more races or international students are retained at high rates. Native students and African American students are retained at very low rates, around $15 \%$.

These retention data are consistent with some previously published work. Some large U.S. engineering programs state that $60-75 \%$ of students who are enrolled in their engineering programs at some point graduate from the university, though not necessarily with an engineering degree [14]-[17] and only about 35-42\% of students stay in engineering [14]-[16].

Course Performance Analysis

Using enrollment management data, we evaluated the transcripts of 621 students who took our introductory chemical engineering 101 course to determine the course choice and grade differences between students who graduated with a chemical engineering degree, those that graduated with a non-chemical engineering degree, and those that dropped out of the university without a degree. Figure 4 below shows the academic career outcome of these students.

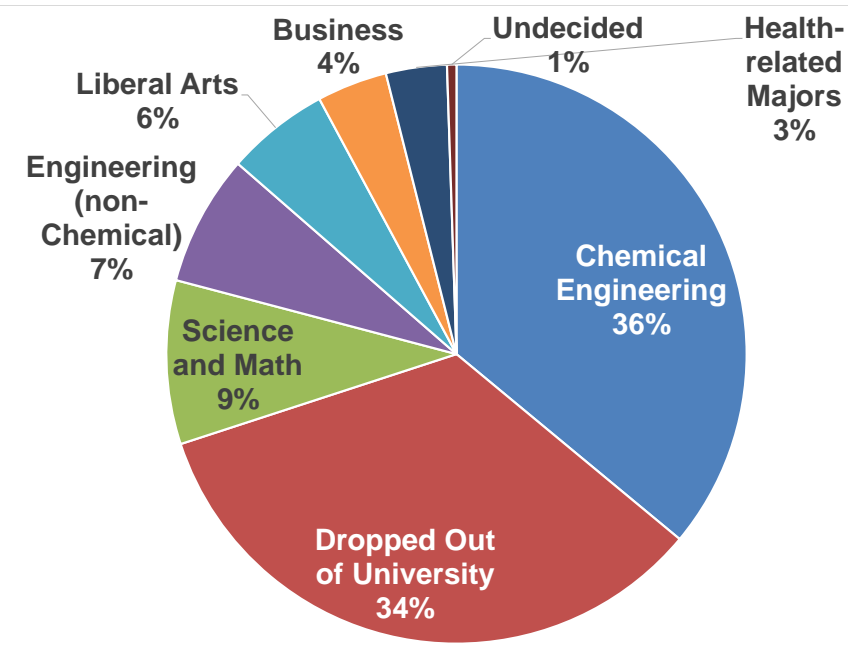

Figure 4: Academic pathways of students who took the introductory 101 chemical engineering course in 2014,2015 , or 2016. $\mathrm{N}=383$. Majors shown in the figure represent students who have graduated from or are currently still enrolled in those majors.

Around $1 / 3$ of the students who took our introductory chemical engineering 101 course earned chemical engineering degrees, another $\sim 1 / 3$ earned other degrees, and the last 1/3 dropped out of the university without a degree. Of the $34 \%$ of students who dropped out of the university, their average number of semesters on campus was 3.5. This prompted us to examine other aspects of course enrollment and performance among the students who dropped out, specifically the 
percentage of students who took remedial math, chemistry courses at any point at our university, shown in Table 1.

Table 1: Percentage of students who take remedial math, chemistry, and physics at our university among students who took the introductory 101 chemical engineering course in 2014, 2015, or 2016. $\mathrm{N}=383$. Whether students took remedial courses at other universities or colleges is unknown.

\begin{tabular}{|r|c|c|c|}
\hline & Math & Chem & Physics \\
\hline Graduated CHE & 27 & 3 & 14 \\
\hline Graduated Science or Math & 56 & 7 & 37 \\
\hline Graduated Other Engineering & 21 & 0 & 0 \\
\hline Graduated Liberal Arts, & & & 17 \\
\hline Business, Health Majors & 66 & 17 & 14 \\
\hline
\end{tabular}

These data show that few students who graduate with chemical engineering degrees take remedial math, physics, or chemistry. Of these three subjects, remedial math is the subject most commonly taken among all students examined, though only $27 \%$ of chemical engineering graduates took one or more remedial math courses. The majority of students who graduated with a liberal arts, business, or health-related major took remedial math, even higher than those who dropped out of the university without a degree.

We also examined the average course grades for remedial as well as required (non-remedial) math, chemistry, and physics courses to determine the differences between chemical engineering graduates and those students who drop out of the university without a degree, shown in Figure 5 below.

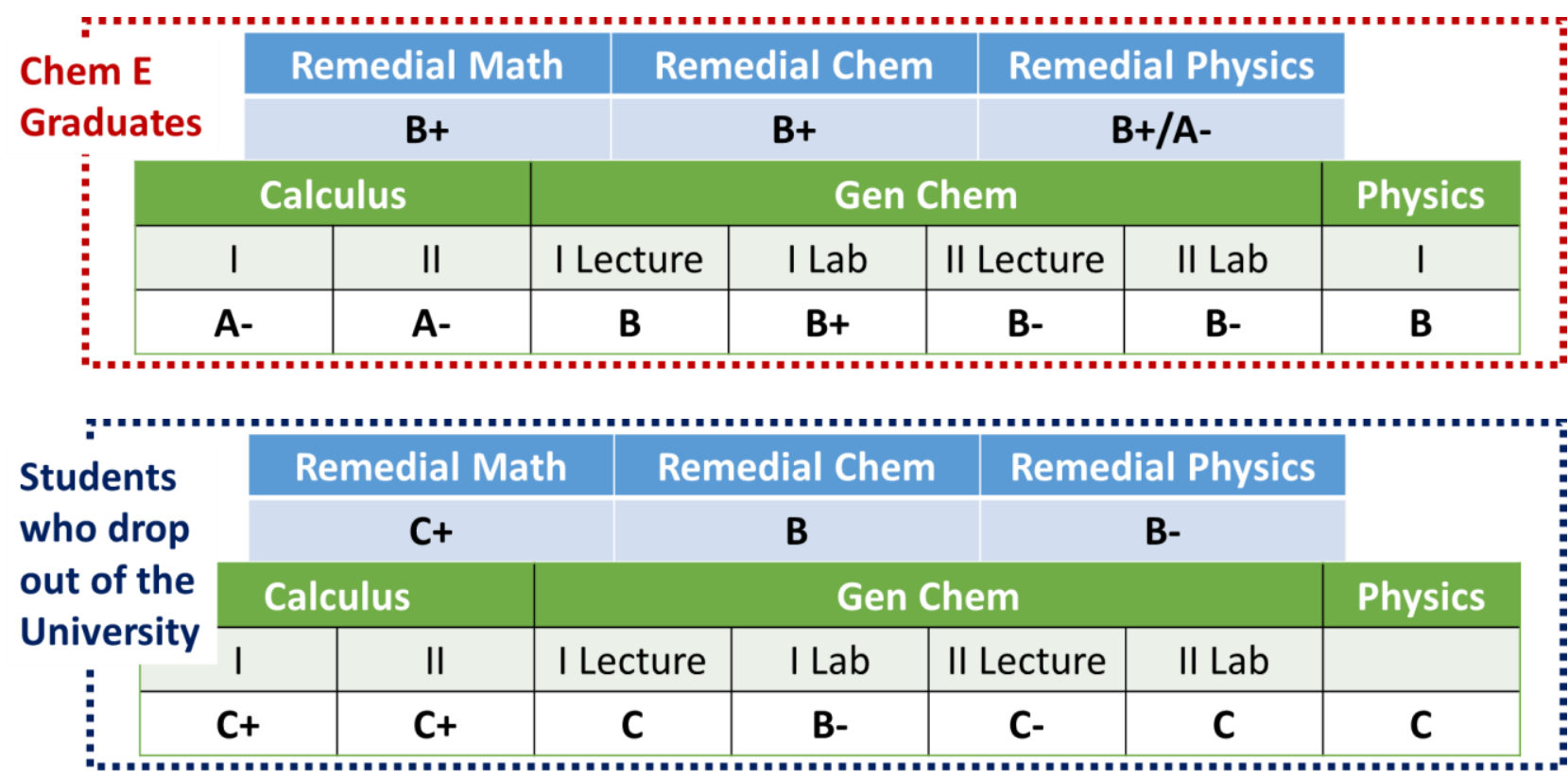

Figure 5: Average remedial and required (non-remedial) math, chemistry, and physics course grades among students who took our introductory 101 chemical engineering course in 2014 , 
2015, or 2016 and either graduated with a chemical engineering degree or dropped out of the university without a degree. $\mathrm{N}=383$.

Chemical engineering graduates earn around a $\mathrm{B}+$ in remedial science and math courses, while students who drop out earn around one letter grade lower in these courses. Chemical engineering graduates earn on average an A- in both calculus courses, while students who drop out earn C+. For chemistry and physics courses, students who graduate with a chemical engineering degree earn around a letter grade higher compared to students who drop of out the university (an average B vs. a C in these courses.) We determined that other engineering graduates (such as nuclear or mechanical engineering graduates) were equally strong in calculus and physics compared to chemical engineering graduates, however their grades were lower for chemistry courses. Science (chemistry, biochemistry, etc.) and math graduates were equally strong in chemistry compared to chemical engineering graduates, however their grades in calculus and physics were lower. Liberal arts, business, and health graduates had lower grades in all three areas, however these grades were higher than those students who dropped out of the university. Clearly, these data suggest students who graduate with chemical engineering degrees tend to be strong in all three subjects and weakness in any one (especially calculus) corresponds with students transferring to another major or dropping out of the university.

We explored further the impact of calculus preparation and its correlation to student attrition in our program. Table 2 examines the transfer credit differences between graduates and students who drop out of the university without a degree.

Table 2: Enrollment of Calculus I at our university, among students who took our introductory chemical engineering 101 course between 2014-2019. N=621. These results are very similar for Calculus II as well.

\begin{tabular}{|c|c|c|c|c|}
\hline CALCULUS I & Took Course & $\begin{array}{l}\text { Tested Out or } \\
\text { Transferred Grade } \\
\text { from Comm. Coll. }\end{array}$ & $\begin{array}{l}\text { Did not enroll in } \\
\text { class }\end{array}$ & Average Grade: \\
\hline $\begin{array}{r}\text { Students who } \\
\text { graduated Chem E }\end{array}$ & 46 & 54 & 0 & $A-$ \\
\hline $\begin{array}{r}\text { Dropped Out of the } \\
\text { University }\end{array}$ & 42 & 16 & 42 & $\mathrm{C}+$ \\
\hline
\end{tabular}

Over half of chemical engineering graduates either test out of or transfer credits for calculus I from a community college or another university, compared to only $16 \%$ of students who drop out of the university. Similar percentages are observed for calculus II, as well as general chemistry I and II courses. Of students who drop out of the university, $42 \%$ never take calculus I, suggesting that these students may have many challenges before their enrollment in calculus, such as difficulty with or lack of interest in prerequisite math courses. The testing out or transferring of credits is obviously determined before they enroll in the university and is a reflection of students' inherent focus on STEM as a career in advance of their university studies.

Our data suggest that for our chemical engineering students, grades in regular and remedial math, chemistry, and physics courses and the prevalence of transfer/test-out credits for these courses are important predictors of retention. These data are in agreement with literature findings which 
correlate persistence in chemical engineering with high school preparation and freshman-level math, chemistry, and physics grades [11].

Implications for Educators

This study has focused on the importance of effective preparation for engineering curricula as a means to improving student retention in engineering. However, we acknowledge that many other studies, as explored in the Introduction, show that climate, department culture, and university culture factors are also important to address in order for retention to be successful, equitable, and attainable for all students.

As we are a Hispanic-serving institution, and because studies have shown that non-White students are more likely to cite technical curriculum difficulty as a reason for leaving [6], this prompts us to ensure students have access to the support they need to succeed in math and science courses. This also places a greater responsibility on individual departments to check in regularly with students throughout their freshman year, during their 101 introductory course, and consistently thereafter to ensure they are on the path to successfully completing subsequent chemical engineering courses. Within the first semester, while the extensive benefits of an engineering degree are conveyed, students should also understand the rigor of math, science, and engineering courses and that they should expect their coursework to be difficult and timeconsuming. This is often best conveyed through a peer mentor who can help model and explain academic expectations and success. These immediate first semester interventions are supported by studies which have proven their effectiveness in engineering programs [18] [19].

\section{Conclusion}

Among our diverse student population we have observed many promising and positive retention outcomes. Among the cohort of students examined, graduates from our program are more likely to have transferred or tested out of many science and math credit requirements and $54 \%$ of our four-year graduates are first-generation college students. Men, women, White students, Latinx students, and Asian students are retained at around 40\%, the same overall rate as all students combined. Our Latinx student retention rate is higher than the national average of 32\% [1]. Overall retention of our students from 1 st to 4 th year is $41 \%$.

Likewise, some attrition observations examined here have provided critical warnings regarding the conditions and likelihood of students dropping out of the university without a degree. Around $1 / 3$ of the students who took our introductory chemical engineering 101 course dropped out of the university. These students were far more likely to take remedial math, chemistry, and physics courses, earn around one letter grade lower in math, chemistry, and physics courses compared to chemical engineering graduates, and were far less likely to have tested out of or transferred credits for these courses.

The results of this study have important implications for students, faculty, and academic advisors. Priorities must be appropriately set at college and department levels to develop approaches to address students' needs. Students who are taking remedial math, chemistry, or physics courses or who are earning B- or C+ grades in regular math, chemistry, or physics 
courses require early intervention within the first 1-3 semesters of their academic career. Faculty in various departments should meet with students to identify the type of help or resources from which they could benefit most. Prior to enrollment in university courses, academic advisors should be alerted to students who have not transferred or tested out of math and science courses and may need to take remedial courses. In addition to faculty mentoring, peer mentoring is an effective way of ensuring that students understand university expectations and are less likely to feel overwhelmed.

Acknowledgments

This material is based upon work supported by the National Science Foundation under Grant No. 1623105, FY17-21. Any opinions, findings, and conclusions or recommendations expressed in this material are those of the authors and do not necessarily reflect the views of the National Science Foundation.

References

[1] J.I. Lane, "Understanding the Educational and Career Pathways of Engineers," National Academies Press, 2019.

[2] B.N. Geisinger and D.R. Raman, "Why they leave: Understanding student attrition from engineering majors," International Journal of Engineering Education, 29(4), p.914. 2013.

[3] C. Adelman, "Women and Men of the Engineering Path: A Model for Analyses of Undergraduate Careers," US Government Printing Office, Superintendent of Documents, Mail Stop: SSOP, Washington, DC 20402-9328, 1998.

[4] W.C. Mau, "Factors that influence persistence in science and engineering career aspirations," The Career Development Quarterly, 51(3), pp.234-243, 2003.

[5] R.M. Felder, G.N. Felder, M. Mauney, C.E. Hamrin Jr., and E.J. Dietz, "A longitudinal study of engineering student performance and retention. III. Gender differences in student performance and attitudes," Journal of Engineering Education, 84(2), pp.151-163, 1995.

[6] R.M. Marra, K.A. Rodgers, D. Shen, and B. Bogue, "Leaving engineering: A multi-year single institution study," Journal of Engineering Education, 101(1), pp.6-27, 2012.

[7] T. Y. Smith, "Science, mathematics, engineering and technology retention database," Research News on Graduate Education, 2(2), 2000.

[8] E. Seymour, and N. M. Hewitt, Talking about leaving: Why undergraduates leave the sciences, Westview Press, CO. 1997.

[9] C. M. Vogt, "Faculty as a critical juncture in student retention and performance in engineering programs," Journal Engineering Education, 97(1), 27-36, 2008.

[10] M. Meyer and S. Marx, "Engineering dropouts: A qualitative examination of why undergraduates leave engineering," Journal of Engineering Education, 103(4), pp.525-548, 2014.

[11] R.M. Felder, K.D. Forrest, L. Baker - Ward, E.J. Dietz, and P.H. Mohr, “A longitudinal study of engineering student performance and retention: I. Success and failure in the introductory course," Journal of Engineering Education, 82(1), pp.15-21, 1993.

[12] M. Miletic, V. Svihla, J.R. Gomez, S.M. Han, E. Chi, S.P. Kang, C. Hubka, Y. Chen, and A.K. Datye, "Assessment of Program-wide Curricular Change," in Proceedings of the ASEE 126th Annual Conference and Exhibition, 2019.

[13] Niche.com [Online]. Available: http://niche.com, [Accessed January 28, 2019]. 
[14] J. M. Fraser and D. R. Ismail, "Analysis of men and women engineering students at Ohio State," in ASEE Annual Conference and Exposition, Conference Proceedings, 1997.

[15] S.J. Lasser and R.W. Snelsire, November. "The case for proactive mentoring for minorities in engineering," in Technology-Based Re-Engineering Engineering Education Proceedings of Frontiers in Education FIE'96 26th Annual Conference November 1996, Vol. 2, pp. 767-769. [16] C. Moller-Wong and A. Eide. "An engineering student retention study." Journal of Engineering Education, 86, (1), pp. 7-15, 1997.

[17] G.S. Jakubowski, G. Lovett, and M. Ehass-Sanz, "External factors that affect the retention of engineers: an urban university perspective" in ASEE Annual Conference and Exposition, Conference Proceedings, 1988.

[18] L. Shuman, C. Delaney, H. Wolfe, A. Scalise, and M. Besterfield-Sacre, "Engineering attrition: Student characteristics and educational initiatives," in Proceedings of the American Society of Engineering Education, Charlotte, NC. 1999.

[19] M. Besterfield-Sacre, C. J. Atman, and L. Shuman, "Characteristics of freshman engineering students: Models for determining student attrition in engineering," Journal of Engineering Education, 86(2), 139- 149, 1997. 